\title{
Astringency sensitivity to tannic acid: effect of ageing and
}

\section{salivary flow.}

\author{
Mei Wang ${ }^{1}$, Chantal Septier ${ }^{1}$, Hélène Brignot ${ }^{1}$, Christophe Martin $^{1}$, Francis Canon ${ }^{1}$ and Gilles Feron ${ }^{1 *}$
}

1 Centre des Sciences du Goût et de l'Alimentation, AgroSup Dijon, CNRS, INRAE, Université Bourgogne Franche-Comté, F-21000 Dijon, France ; mei.wang@inrae.fr

1 Centre des Sciences du Goût et de l'Alimentation, AgroSup Dijon, CNRS, INRAE, Université Bourgogne Franche-Comté, F-21000 Dijon, France ; chantal.septier@inrae.fr

1 Centre des Sciences du Goût et de l'Alimentation, AgroSup Dijon, CNRS, INRAE, Université Bourgogne Franche-Comté, F-21000 Dijon, France ; helene.brignot@inrae.fr

1 Centre des Sciences du Goût et de l'Alimentation, AgroSup Dijon, CNRS, INRAE, Université Bourgogne Franche-Comté, F-21000 Dijon, France ; christophe.martin@inrae.fr

1 Centre des Sciences du Goût et de l'Alimentation, AgroSup Dijon, CNRS, INRAE, Université Bourgogne Franche-Comté, F-21000 Dijon, France ; francis.canon@inrae.fr

1 Centre des Sciences du Goût et de l'Alimentation, AgroSup Dijon, CNRS, INRAE, Université Bourgogne Franche-Comté, F-21000 Dijon, France ; gilles.feron@inrae.fr

* Correspondence: gilles.feron@inrae.fr

\begin{abstract}
Astringency is an important sensory characteristic of food and beverages containing polyphenols. However, astringency perception in elderly people has not been documented. The aim of the present work was to evaluate sensitivity to astringency as a function of age and salivary flow. Fifty-four panellists, including 30 elderly people (age $=75 \pm 4.2$ years) and 24 young people (age $=29.4 \pm 3.8$ years), participated in this study. Astringency sensitivity was evaluated by the 2-alternative forced choice (2-AFC) procedure using tannic acid solutions. Whole saliva was collected for $5 \mathrm{~min}$ before and after sensory tests. The results showed that the astringency threshold was significantly higher in the elderly group than in the young group. Moreover, a negative correlation between salivary flow and threshold was observed in the young group only. These results showed a difference in oral astringency perception as a function of age for the first time. This difference can be linked to salivary properties that differ as a function of age.
\end{abstract}

Keywords: astringency; threshold; saliva; elderly; tannic acid

\section{Introduction}

Dietary polyphenols are a class of compounds present in some foods and beverages, such as vegetables, nuts, unripe fruits, wine and tea [1-3]. They are of great interest for the food industry because of their potential beneficial effects on health, particularly for the ageing population [4, 5]. In food and beverages, polyphenols, especially tannins, can elicit astringency, which is perceived as a quality parameter and desired at balanced levels depending on the food products [6-8]. In contrast, above a certain intensity, astringency is usually described as a unpleasant oral sensation [9], limiting the use and promotion of polyphenols at moderate levels in food despite their health benefits [10]. It should also be considered that at high levels, tannins can also have antinutritional effects [11]. Several mechanisms have been proposed for astringency [10] onset, but recent results indicate that it most likely relies on the interactions of tannins with the mucosal pellicle [9, 12], causing the aggregation of this thin layer of salivary proteins anchored at the surface of the oral mucosa via their interaction with MUC1, a transmembrane protein [13]. This aggregation has been correlated with an increase in the friction forces at the surface of epithelial cells [9]. This observation indicates that the mucosal pellicle loses its lubricating properties during the aggregation process. In this hypothesis, astringency can be modulated by the 
presence of proline-rich proteins (PRPs) in saliva. Indeed, PRPs, which are secreted by the parotid glands, bind and scavenge tannins [14], giving them the ability to protect the mucosal pellicle against tannin aggregation. The perception of astringency is not confined to a particular region of the mouth or tongue and is perceived as a diffuse stimulus. It is basically a dynamic process that continuously changes or evolves to reach a maximum intensity, which may require $15 \mathrm{~s}$ or more to develop fully [15]. Thus, astringency is often the last sensation detected [16]. Moreover, Lyman found that the perception of mouth dryness increases with repeated exposures to an astringent stimulus, which suggests that astringency is a cumulative sensation [17]. In agreement with the hypothesis proposed above, this observation suggests that repeated exposure to tannins increases the number of tannins bound to the mucosal pellicle.

Regarding the effect of ageing on astringency perception, the literature is quite scarce, although ageing is a common main factor that affects flavour perception [18-20]. Beyond this overall effect of age on chemosensory abilities, ageing is accompanied by interindividual variability in olfactory performance scores and, to a lesser degree, in taste performance scores [21].

Reasons for these modifications on olfactory and taste perception can be linked to changes in oral physiology with age. Indeed, in the elderly population, the cumulative effects of physiological ageing, diseases and drugs frequently impact the different aspects of oral physiology that are of great importance in taste and aroma sensitivity and thus eating behaviour [18, 22]. In particular, ageing may often be accompanied by a decrease in salivary flow or changes in salivary composition, which can lead to dry mouth or xerostomia. Hyposalivation is common among older adults due to an age-related decline in salivary gland function; other causes of hyposalivation include medications and systemic diseases [23]. Recently, Descamps et al. [24] determined an average 38.5\% reduction in resting salivary flow and a $38 \%$ reduction in stimulated salivary flow in healthy elderly people compared to young adults. This salivary hypofunction in elderly individuals can lead to changes in aroma and taste perception $[25][26,27]$ and, more globally, in food consumption [22].

In the context of the world population becoming older and ageing well, the main objective of this study was to investigate the sensitivity to astringency as a function of age and salivary flow. For this purpose, a 2-alternative forced choice (2-AFC) methodology was applied to estimate astringency sensitivity in young and elderly panels while evaluating salivary flow. Relationships between salivary flow and sensitivity as a function of age are discussed.

\section{Materials and Methods}

This study was approved on 31 October 2019 by the Ethical Committee CCP Ile de France IV under the number 2019-A02434-53.

\subsection{Materials}

Solutions for rinsing consisted of $0.1 \%$ pectin (Sigma-Aldrich, France) and 1\% bicarbonate (Gilbert, France) dissolved in Evian water at room temperature.

Solutions for the sensory training session consisted of six taste solutions (salty, sour, sweet, bitter, umami, and astringent), whose composition is detailed in Table S1 (supplementary material). Each solution was coded with random three-digit codes.

Solutions for astringency sensitivity evaluation consisted of four solutions with increasing tannic acid concentrations (in g/L) with a multiple of 3.05, i.e., 0.02, 0.062, 0.188, and 0.574 , respectively. These concentrations were chosen on the basis of preliminary experiments performed with a small internal panel of subjects. All samples were prepared in Evian water 1 hour before testing at room temperature. Since potassium alum has not been allowed in sensory studies, tannic acid was used as a component to evaluate astringency because it has been described as less bitter than other polyphenols, such as gallic 
acid and catechin [28], and thus limits confusion between astringency and bitter. This was confirmed during preliminary tests.

\subsection{Sensory analysis}

Fifty-four panellists, including 30 elderly $(\mathrm{O})$ people and 24 young $(\mathrm{Y})$ people, were recruited to participate in the sensory sessions. The panel is described in Table 3 . The number of subjects was determined by a power test. Based on preliminary results obtained on the internal panel, a number of at least 23 subjects per group ( $\mathrm{Y}$ or $\mathrm{O}$ ) was necessary to observe a difference equal to at least one standard deviation between the groups. More subjects were recruited in case of defection.

\subsection{Training session}

The first training session was divided into two parts. During the first part, subjects received $20 \mathrm{~mL}$ of each tasting sample in a fixed order at room temperature in plastic cups coded with random numbers. They were instructed to put the samples into their mouths, swirl the sample gently in the mouth for $30 \mathrm{~s}$, spit it out and judge which taste it was. Between samples, subjects rinsed their mouth with Evian water and then waited for $1 \mathrm{~min}$ before the next sample. In the second part, subjects were trained for the 2-AFC procedure using astringency stimuli as described below.

During both parts of the training session, there was a discussion between subjects and experimenters after each test. The objective for the experimenters was to be sure that subjects were able to (i) clearly identify and differentiate astringency from other sensory sensations, in particular bitterness, and (ii) perfectly understood the procedure of the sensory test, i.e., the 2-AFC to be used later.

The whole session was conducted under red light to eliminate colour differences.

\subsection{Testing session}

The whole session was conducted under red light at room temperature in a sensory room equipped with individual boxes.

At the beginning of each session, panellists were asked to taste a model tannic acid solution of $1.76 \mathrm{~g} / \mathrm{L}$ to be well aware of astringency. Then, they rinsed their mouths with pectin, bicarbonate and Evian water [29] and waited for a 3 min break before threshold evaluation.

The astringency threshold was evaluated by a 2-AFC procedure with ascending concentrations of tannic acid as described above in the Materials section. In each 2-AFC presentation, two samples were presented: one was the target sample, and one was the control. Each 2-AFC test was performed 3 times, and evaluation was performed 3 times in 3 different sessions. Pair samples $(5 \mathrm{~mL})$ were presented in balanced order following a Latin square (Williams design) at room temperature in a white plastic cup coded with the letter A or B. The testing procedure started from the lowest concentration. Panellists were given the reference or stimulus sample. They were asked to put the samples into their mouth, swirl them gently around the mouth for $30 \mathrm{~s}$ and then spit them out. They rinsed their mouths with pectin and waited for $1 \mathrm{~min}$ before evaluating the second sample. After one additional minute, the panellists were asked to indicate which sample was perceived as astringent. Then, the panellists rinsed their mouth with pectin, bicarbonate and Evian water before performing another 2-AFC test.

The sensitivity level was reached when three correct answers from the same concentration were achieved. The best estimate threshold for each subject was evaluated as the geometric mean of the three correctly answered concentrations and the previous lower concentration. When subjects correctly identified the lowest concentration $(0.02 \mathrm{~g} / \mathrm{l})$, the geometric means were calculated between this concentration and the theoretical concentration below, i.e., $0.02 / 3.05=0.0065 \mathrm{~g} / \mathrm{l}$. In contrast, when subjects did not correctly identify the highest concentration $(0.574 \mathrm{~g} / \mathrm{l})$, the geometric mean was calculated between this concentration and the theoretical concentration above, i.e., $0.574^{*} 3.05=1.75 \mathrm{~g} / \mathrm{l}$. 


\subsection{Saliva collection}

Whole saliva was collected after the panellists had rinsed their mouths with $0.1 \%$ pectin, $1 \%$ bicarbonate and water at the start (SFStart) and at the end (SFEnd) of the session. Saliva was collected by expectorating saliva into a pre-weighed tube with a cap for $5 \mathrm{~min}$ as described previously [30]. After collection, the tubes were weighed and then stored at $-80^{\circ} \mathrm{C}$. Flow rates were determined gravimetrically and expressed as grams per minute $(\mathrm{g} / \mathrm{min})$.

\subsection{Statistical analysis}

Non-parametric analyses were conducted. Mann-Whitney $U$ tests were performed to evaluate differences between $\mathrm{Y}$ and $\mathrm{O}$ subjects regarding sensory and salivary parameters. Wilcoxon tests were performed to evaluate differences between SFStart and SFEnd. Friedman ANOVA was conducted on threshold and salivary flux measurements to evaluate differences between the three sessions. Spearman rank order correlations were performed for the whole group and in each group $(\mathrm{Y}$ and $\mathrm{O})$ to evaluate relationships between salivary and sensory parameters. The significancy was set at $\mathrm{p}<0.05$. These tests were performed using Statistica ${ }^{\circledR}$ version 13.5.0.17, 1984-2018 TIBCO Software Inc.

\section{Results}

\subsection{Salivary flow rate}

No significant differences were observed between sessions regarding SFStart and SFEnd for either group Y (SFStart: Friedman chi2 $=0.75, \mathrm{p}=0.68$; SFEnd: Friedman chi2 $=0.75, p=0.68$ ) or group O (SFStart: Friedman chi2 $=5.2, p=0.07$; SFEnd: Friedman chi2=1.3, $p=0.53)$ or between the mean SFStart and mean SFEnd for the $Y(Z=0.68, p=0.492)$ and $O$ groups $(Z=1.49, p=0.135)$. For this reason, we decided to merge both variables into a unique variable, i.e., mean salivary flow (SF). SF values are presented in Figure 1. With regard to the comparison of salivary flow rate, there was no significant difference in SF between the $\mathrm{Y}$ and $\mathrm{O}$ groups $(\mathrm{Z}=1.66, \mathrm{p}=0.09)$ (Table 1$)$.

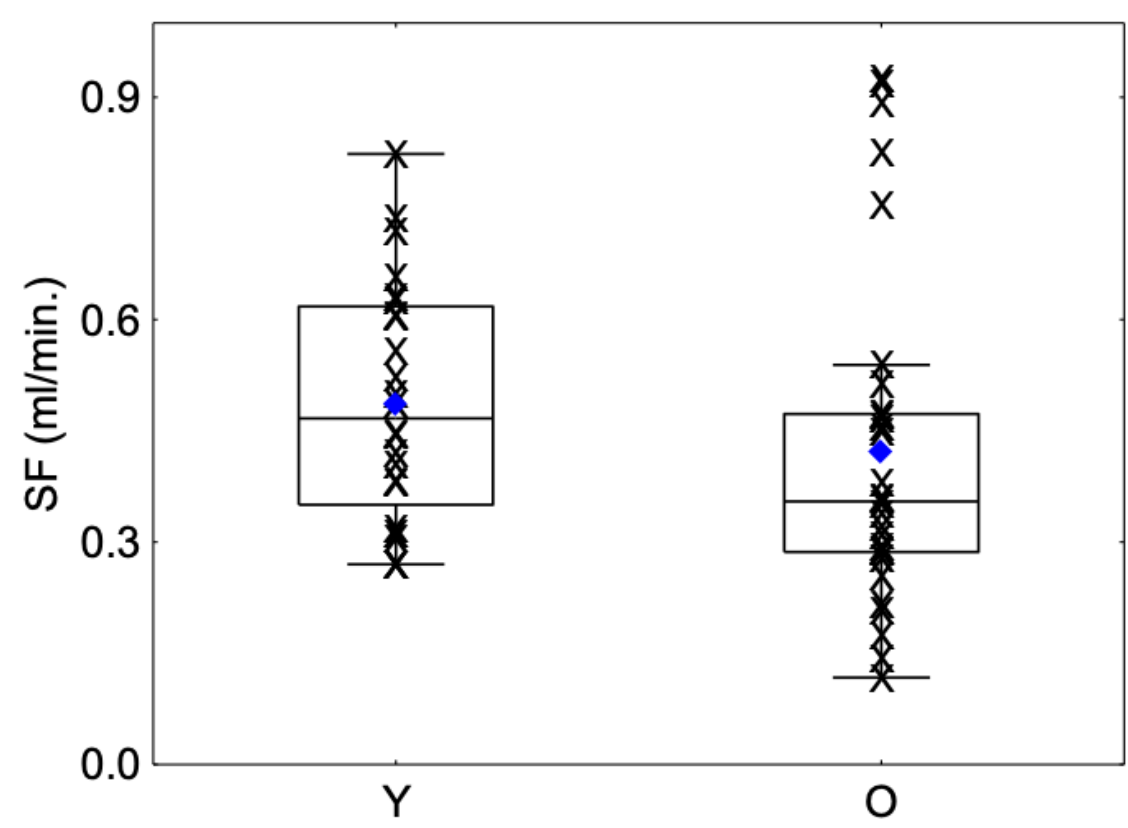

Figure 1: Box-plot distributions of whole salivary flux as a function of age category (young (Y) and elderly (O)) are shown. The bottom and top of the box correspond to the 25 th and 75 th percentiles, respectively. The horizontal band and the blue diamond correspond to the median and the mean, respectively. The ends of the whiskers represent the non-outlier range. The $\mathrm{X}$ symbol corresponds to individual data points. 
Table 1. Characteristics of the young and elderly panels

\begin{tabular}{lcccccccc}
\hline & \multicolumn{3}{c}{ Y (n=24, 18 Males/6 Females) } & \multicolumn{4}{c}{ O (n=320, 16 Males/14 Females) } \\
\hline Characteristic & Mean & Median & Range & SD & Mean & Median & Range & SD \\
\hline Age (years) & 29.4 & 30 & $24-35$ & 3.8 & 75 & 73.5 & $70-87$ & 4.23 \\
SFStart (ml/min) & 0.47 & 0.47 & $0.26-0.73$ & 0.14 & 0.44 & 0.36 & $0.23-1$ & 0.24 \\
SFEnd (ml/min) & 0.51 & 0.45 & $0.23-1.03$ & 0.21 & 0.41 & 0.33 & $0.19-0.91$ & 0.23 \\
SF (ml/min) & 0.49 & 0.47 & $0.27-0.82$ & 0.16 & 0.42 & 0.35 & $0.11-0.92$ & 0.23 \\
Threshold (g/L) & 0.29 & 0.2 & $0.04-1.00$ & 0.26 & 0.41 & 0.35 & $0.06-0.78$ & 0.24 \\
\hline
\end{tabular}

SD: standard deviation of the mean

\subsection{Astringency threshold}

No significant differences were observed between the three sessions regarding astringency thresholds for either group $\mathrm{Y}$ (Friedman chi2 $=1.13, \mathrm{p}=0.56$ ) or group $\mathrm{O}$ (Friedman chi2=1.14, $\mathrm{p}=0.56$ ).

A significant difference was observed between the $\mathrm{Y}$ and $\mathrm{O}$ groups $(\mathrm{Z}=-2.5, \mathrm{P}=0.0110)$. The $\mathrm{O}$ group showed a higher mean astringency threshold than the $\mathrm{Y}$ group (Table 1, Figure 2).

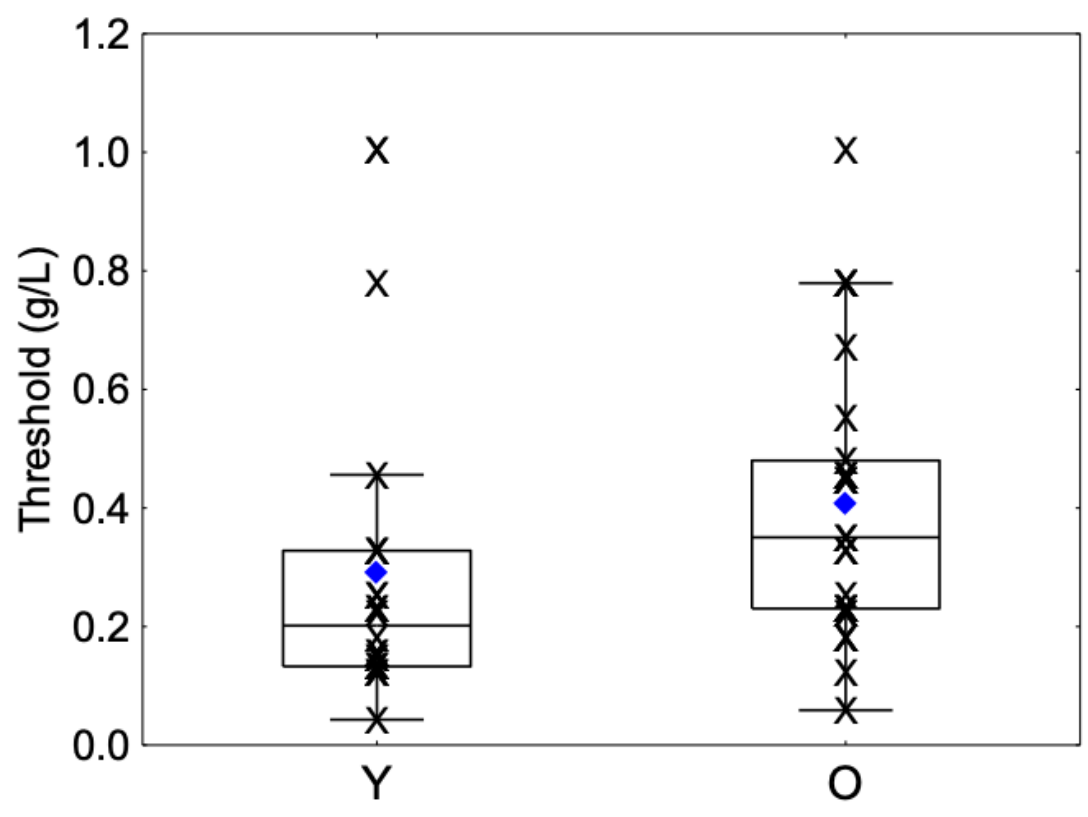

Figure 2: Box-plot distributions of threshold values as a function of age category (young $(\mathrm{Y})$ and elderly $(\mathrm{O})$ ) are shown. The bottom and top of the box correspond to the 25th and 75th percentiles, respectively. The horizontal band and the blue diamond correspond to the median and the mean, respectively. The ends of the whiskers represent non-outlier ranges. The $\mathrm{X}$ symbol corresponds to individual data points.

\subsection{Correlation between astringency threshold and flow rate}

The Spearman correlation was not significant in the whole panel $(r=-0.16, p=0.242)$ or the $\mathrm{O}(\mathrm{r}=0.14, \mathrm{p}=0.47)$ group. However, a significant and negative correlation was observed in the young $(\mathrm{Y})$ group $(\mathrm{r}=-0.44, \mathrm{p}=0.029)$, where higher salivary flow was associated with a lower threshold (Figure 3 ). 


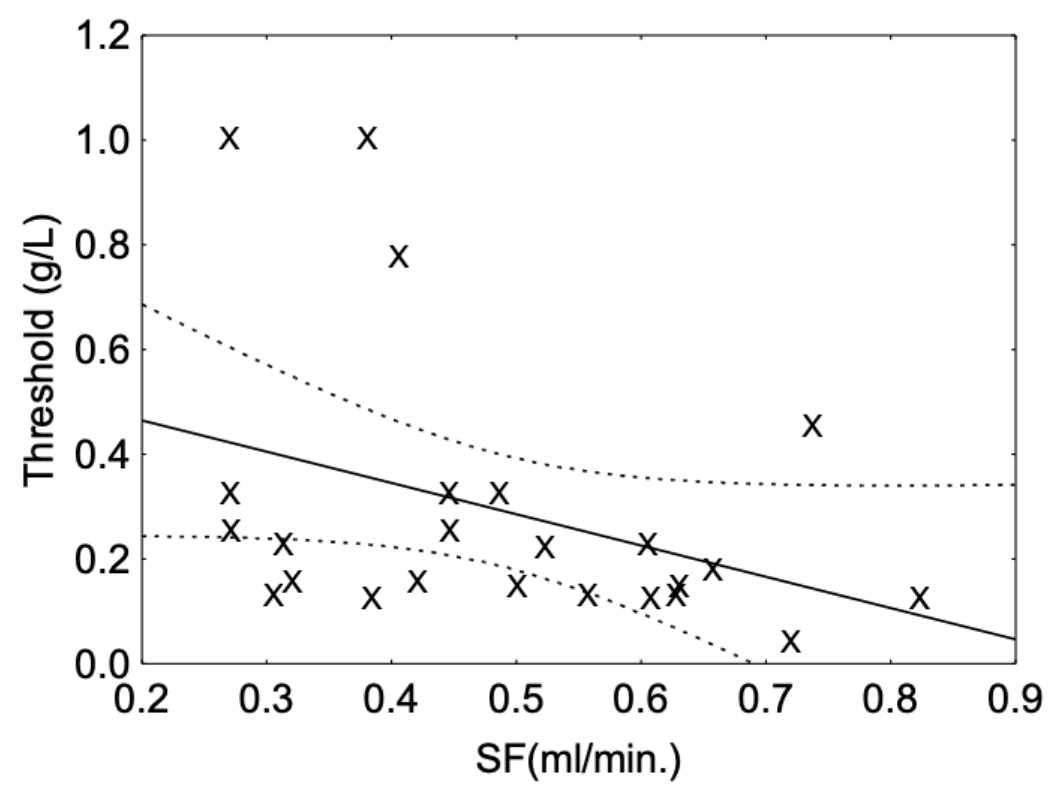

Figure 3: Spearman correlation between astringency threshold and whole salivary flux observed in the group of young panelists. The plain line corresponds to fitted data. The dotted line corresponds to the confidence interval at $95 \%$. The $\mathrm{X}$ symbol corresponds to individual data points.

\section{Discussion}

Astringency is a complex group of sensations involving drying, roughing and puckering of the oral surface, mucosa and muscles around the mouth. To the best of our knowledge, very few studies have investigated sensitivity to astringency as a function of age. In this study, it was observed for the first time that the astringency threshold was significantly higher in elderly participants than in young participants. In other words, young adults are more sensitive to astringency than elderly adults.

Differences in salivary properties can explain differences regarding taste sensitivity and, in particular, the flux. Indeed, saliva is present in the oral cavity and constantly bathes the taste buds on the tongue, where it can interact with sensory stimulants and play a role in taste, smell, and chemosensation [31, 32]. In regard to astringency, the salivary flow rate has been reported to modulate its perception [33], i.e., subjects with low salivary flow rated astringency higher and recorded a longer duration of astringent aftertaste than subjects with a high salivary flow. It has been proposed that there is a negative correlation between resting salivary flow and astringency perceived intensity [34]. Moreover, a subject group with a high salivary flow rate was shown to perceive astringency intensity at a significantly lower level than a low flow rate group [35].

In the present study, this negative relationship was significantly observed in the young panel only, which is in accordance with the studies mentioned previously. However, we did not observe such relationships in the elderly group or a difference in salivary flow between the $\mathrm{Y}$ and $\mathrm{O}$ groups, which should explain the difference in sensitivity between the two groups. These observations suggest that the role of saliva in astringency sensitivity as a function of age should be linked to other salivary parameters, such as its protein composition and, in particular, the level of PRPs.

Indeed, the secretion of basic proline-rich proteins (bPRPs) in mammalian saliva has been shown to be related to the tannin content of the mammalian diet [36]. In humans, an increase in PRPs has been observed in relation to the level of exposure to polyphenols during consumption of chocolate in the diet [37]. Moreover, bPRPs have a high affinity for tannins [38] and, as such, are proteins identified as contributing potentially to astringency perception in humans, while their role in the underlying mechanism of this perception is still under debate [9]. In one study it was proposed that the aggregation of bPRP 
by tannins triggers astringency perception [39]. However, the function of bPRP is more likely to scavenge and neutralize tannins, as they do not have essential amino acids in their sequence [36]. In agreement with this hypothesis, it has been shown that the removal of saliva increases the perceived intensity of astringency. Thus, bPRP, by scavenging tannins, more likely protects the mucosal pellicle against tannins and thus decreases the perception of astringency. In regard to the effect of age, there is a paucity of information describing salivary bPRP amount during the human life span. Exploring salivary exocrine protein secretion in 220 adults, Baum et al. [40] did not find a change in PRP secretion during ageing, but this study considered only acidic PRP. Thoroughly exploring the relation between the bPRP pattern of secretion in the ageing population and astringency sensitivity deserves further investigation.

\section{Conclusions}

In summary, the present study highlighted the sensory analysis of astringency perception sensitivity as a function of age and saliva from a panel formed by 30 elderly people and 24 young people using the 2-AFC method with four tannic acid concentrations. This work has demonstrated for the first time the difference in the astringency threshold between young and elderly people. We conclude that the astringency threshold was higher in the elderly group than in the young group. In regard to the salivary flow rate, there were no significant differences between the young and elderly groups. However, a correlation between salivary flow and threshold was observed only for young individuals, which suggests that salivary properties that influence astringency sensitivity in elderly individuals are different.

Supplementary Materials: Table S1: Description of the tasting solutions used for the training session

Author Contributions: Conceptualization: M.W., C.S., H.B., C.M., F.C. and G.F.; methodology: M.W., C.S., C.M., F.C. and G.F.; formal analysis: M.W. and G.F.; resources: G.F. and F.C.; data curation: M.W. and G.F.; writing - original draft preparation: M.W., F.C. and G.F.; supervision: F.C. and G.F. All authors have read and agreed to the published version of the manuscript.

Funding: Mei Wang received scholarship funding from the China Scholarship Council (China). This work was supported by grants from the GIRACT foundation (Switzerland), the Conseil Régional Bourgogne, Franche-Comte (PARI grant) and the FEDER (European Funding for Regional Economical Development.

Data Availability Statement: The original data presented in this study are available upon request. However, because of ethical or privacy issues, they will be provided in aggregated form.

Acknowledgments: The authors thank the Chemosens platform for providing all facilities to perform sensory studies.

Conflicts of Interest: The authors declare no conflict of interest. The funders had no role in the design of the study, in the collection, analyses, or interpretation of data, in the writing of the manuscript, or in the decision to publish the results.

Institutional Review Board Statement: This study was approved on 31 October 2019 by the Ethical Committee CCP Ile de France IV under the number 2019-A02434-53.

Informed Consent Statement: Informed consent was obtained from all subjects involved in the study.

\section{References}

1. Kiokias, S., C. Proestos, and V. Oreopoulou, Phenolic Acids of Plant Origin-A Review on Their Antioxidant Activity In Vitro (O/W Emulsion Systems) Along with Their in Vivo Health Biochemical Properties. Foods, 2020. 9(4).

2. Troilo, M., G. Difonzo, V.M. Paradiso, C. Summo, and F. Caponio, Bioactive Compounds from Vine Shoots, Grape Stalks, and Wine Lees: Their Potential Use in Agro-Food Chains. Foods, 2021. 10(2).

3. Dilucia, F., V. Lacivita, A. Conte, and M.A. Del Nobile, Sustainable Use of Fruit and Vegetable By-Products to Enhance Food Packaging Performance. Foods, 2020. 9(7). 
4. Mak, T.N. and S. Caldeira, The role of nutrition in active and healthy ageing. Luxembourg: Publications Office of the European Union: EUR, 2014. 26666.

5. Chen, S.-Q., Z.-S. Wang, Y.-X. Ma, W. Zhang, J.-L. Lu, Y.-R. Liang, and X.-Q. Zheng, Neuroprotective Effects and Mechanisms of Tea Bioactive Components in Neurodegenerative Diseases. Molecules, 2018. 23(3).

6. Soares, S., I. Garcia-Estevez, R. Ferrer-Galego, N.F. Bras, E. Brandao, M. Silva, N. Teixeira, F. Fonseca, S.F. Sousa, F. Ferreira-daSilva, N. Mateus, and V. de Freitas, Study of human salivary proline-rich proteins interaction with food tannins. Food Chemistry, 2018. 243: p. 175-185.

7. He, M., H. Tian, X. Luo, X. Qi, and X. Chen, Molecular Progress in Research on Fruit Astringency. Molecules, 2015. 20(1).

8. Soares, S., E. Brandão, C. Guerreiro, S. Soares, N. Mateus, and V. de Freitas, Tannins in Food: Insights into the Molecular Perception of Astringency and Bitter Taste. Molecules, 2020. 25(11).

9. Ployon, S., M. Morzel, C. Belloir, A. Bonnotte, E. Bourillot, L. Briand, E. Lesniewska, J. Lherminier, E. Aybeke, and F. Canon, Mechanisms of astringency: Structural alteration of the oral mucosal pellicle by dietary tannins and protective effect of bPRPs. Food chemistry, 2018. 253: p. 79-87.

10. Pires, M.A., L.M. Pastrana, P. Fuciños, C.S. Abreu, and S.M. Oliveira, Sensorial Perception of Astringency: Oral Mechanisms and Current Analysis Methods. Foods, 2020. 9(8).

11. Mehansho, H., L.G. Butler, and D.M. Carlson, Dietary tannins and salivary proline-rich proteins: interactions, induction, and defense mechanisms. Annual review of nutrition, 1987. 7(1): p. 423-440.

12. Canon, F., C. Belloir, E. Bourillot, H. Brignot, L. Briand, G. Feron, E. Lesniewska, C. Nivet, C. Septier, M. Schwartz, C. Tournier, R. Vargiolu, M. Wang, H. Zahouani, and F. Neiers, Perspectives on Astringency Sensation: An Alternative Hypothesis on the Molecular Origin of Astringency. Journal of Agricultural and Food Chemistry, 2021.

13. Aybeke, E.N., S. Ployon, M. Brulé, B. De Fonseca, E. Bourillot, M. Morzel, E. Lesniewska, and F. Canon, Nanoscale Mapping of the Physical Surface Properties of Human Buccal Cells and Changes Induced by Saliva. Langmuir, 2019. 35(39): p. 12647-12655.

14. Canon, F., S. Ployon, J.-P. Mazauric, P. Sarni-Manchado, M. Réfrégiers, A. Giuliani, and V. Cheynier, Binding site of different tannins on a human salivary proline-rich protein evidenced by dissociative photoionization tandem mass spectrometry. Tetrahedron, 2015. 71(20): p. 3039-3044.

15. Jöbstl, E., J. O'Connell, J.P.A. Fairclough, and M.P. Williamson, Molecular model for astringency produced by polyphenol/protein interactions. Biomacromolecules, 2004. 5(3): p. 942-9.

16. Kallithraka, S., J. Bakker, M.N. Clifford, and L. Vallis, Correlations between saliva protein composition and some T-I parameters of astringency. Food Quality and Preference, 2001. 12(2): p. 145-152.

17. Lyman, B.J. and B.G. Green, Oral astringency - effects of repeated exposure and intercations with sweeteners. Chemical Senses, 1990. 15(2): p. 151-164.

18. Schwartz, C., M. Vandenberghe-Descamps, C. Sulmont-Rossé, C. Tournier, and G. Feron, Behavioral and physiological determinants of food choice and consumption at sensitive periods of the life span, a focus on infants and elderly. Innovative Food Science \& Emerging Technologies, 2018. 46(April): p. 91-106.

19. Methven, L., V.J. Allen, C.A. Withers, and M.A. Gosney, Ageing and taste. Proceedings of the nutrition society, 2012. 71(4): p. 556-565.

20. Mojet, J., E. Christ-Hazelhof, and J. Heidema, Taste perception with age: generic or specific losses in threshold sensitivity to the five basic tastes? Chemical senses, 2001. 26(7): p. 845-860.

21. Sulmont-Rossé, C., I. Maître, M. Amand, R. Symoneaux, V. Van Wymelbeke, E. Caumon, J. Tavarès, and S. Issanchou, Evidence for different patterns of chemosensory alterations in the elderly population: impact of age versus dependency. Chemical Senses, 2015. 40(3): p. 153-64.

22. Muñoz-González, C., M. Vandenberghe-Descamps, G. Feron, F. Canon, H. Labouré, and C. Sulmont-Rossé, Association between salivary hypofunction and food consumption in the elderlies. A systematic literature review. The journal of nutrition, health \& aging, 2018. 22(3): p. 407-419.

23. Iwasaki, M., A. Yoshihara, K. Ito, M. Sato, K. Minagawa, K. Muramatsu, R. Watanabe, M.C. Manz, T. Ansai, and H. Miyazaki, Hyposalivation and dietary nutrient intake among community-based older Japanese. Geriatrics \& gerontology international, 2016. 16(4): p. 500-7.

24. Vandenberghe-Descamps, M., H. Labouré, A. Prot, C. Septier, C. Tournier, G. Feron, and C. Sulmont-Rossé, Salivary flow decreases in healthy elderly people independently of dental status and drug intake. Journal of Texture Studies, 2016. 47: p. 353-360.

25. Muñoz-González, C., M. Brulé, G. Feron, and F. Canon, Does interindividual variability of saliva affect the release and metabolization of aroma compounds ex vivo? The particular case of elderly suffering or not from hyposalivation. Journal of Texture Studies, 2019. 50(1): p. 36-44.

26. Criado, C., C. Muñoz-González, and M.Á. Pozo-Bayón, Differences in salivary flow and composition between age groups are correlated to dynamic retronasal aroma perception during wine consumption. Food Quality and Preference, 2021. 87: p. 104046.

27. Spence, C. and J. Youssef, Aging and the (Chemical) Senses: Implications for Food Behaviour Amongst Elderly Consumers. Foods, 2021. 10(1).

28. Robichaud, J.L. and A.C. Noble, Astringency and bitterness of selected phenolics in wine. Journal of the Science of Food and Agriculture, 1990. 53(3): p. 343-353.

29. Esteban-Fernández, A., N. Rocha-Alcubilla, C. Muñoz-González, M.V. Moreno-Arribas, and M.Á. Pozo-Bayón, Intra-oral adsorption and release of aroma compounds following in-mouth wine exposure. Food Chemistry, 2016. 205: p. 280-288. 
30. Neyraud, E., O. Palicki, C. Schwartz, S. Nicklaus, and G. Feron, Variability of human saliva composition: Possible relationships with fat perception and liking. Archives of Oral Biology, 2012. 57(5): p. 556-566.

31. Matsuo, R., Role of Saliva in the Maintenance of Taste Sensitivity. Journal of Dental Research, 2000. 11(2): p. $216-229$.

32. Feron, G., Unstimulated saliva: background noise in taste molecules. Journal of texture studies, 2018.

33. Ishikawa, T. and A.C. Noble, Temporal perception of astringency and sweetness in red wine. Food Quality and Preference, 1995. 6(1): p. 27-33.

34. Horne, J., J. Hayes, and H.T. Lawless, Turbidity as a Measure of Salivary Protein Reactions with Astringent Substances. Chemical Senses, 2002. 27(7): p. 653-659.

35. Fischer, U., R.B. Boulton, and A.C. Noble, Physiological factors contributing to the variability of sensory assessments: Relationship between salivary flow rate and temporal perception of gustatory stimuli. Food Quality and Preference, 1994. 5(1-2): p. 55-64.

36. Shimada, T., Salivary Proteins as a Defense Against Dietary Tannins. Journal of Chemical Ecology, 2006. 32(6): p. $1149-1163$.

37. Crawford, C.R. and C.A. Running, Addition of chocolate milk to diet corresponds to protein concentration changes in human saliva. Physiology \& Behavior, 2020. 225: p. 113080.

38. Hagerman, A.E. and L.G. Butler, The specificity of proanthocyanidin-protein interactions. Journal of Biological Chemistry, 1981. 256(9): p. 4494-4497.

39. Canon, F., F. Paté, V. Cheynier, P. Sarni-Manchado, A. Giuliani, J. Pérez, D. Durand, J. Li, and B. Cabane, Aggregation of the Salivary Proline-Rich Protein IB5 in the Presence of the Tannin EgCG. Langmuir, 2013. 29(6): p. 1926-1937.

40. Baum, B.J., E.E. Kousvelari, and F.G. Oppenheim, Exocrine Protein Secretion from Human Parotid Glands during Aging: Stable Release of the Acidic Proline-Rich Proteins. Journal of Gerontology, 1982. 37(4): p. 392-395. 